\title{
Daytime sleep duration and the development of childhood overweight: the KOALA Birth Cohort Study
}

Citation for published version (APA):

Bolijn, R., Gubbels, J. S., Sleddens, E. F., Kremers, S. P., \& Thijs, C. (2016). Daytime sleep duration and the development of childhood overweight: the KOALA Birth Cohort Study. Pediatric Obesity, 11(5), e1-e5. https://doi.org/10.1111/ijpo.12043

Document status and date:

Published: 01/10/2016

DOI:

10.1111/ijpo.12043

Document Version:

Publisher's PDF, also known as Version of record

Document license:

Taverne

Please check the document version of this publication:

- A submitted manuscript is the version of the article upon submission and before peer-review. There can be important differences between the submitted version and the official published version of record.

People interested in the research are advised to contact the author for the final version of the publication, or visit the DOI to the publisher's website.

- The final author version and the galley proof are versions of the publication after peer review.

- The final published version features the final layout of the paper including the volume, issue and page numbers.

Link to publication

\footnotetext{
General rights rights.

- You may freely distribute the URL identifying the publication in the public portal. please follow below link for the End User Agreement:

www.umlib.nl/taverne-license

Take down policy

If you believe that this document breaches copyright please contact us at:

repository@maastrichtuniversity.nl

providing details and we will investigate your claim.
}

Copyright and moral rights for the publications made accessible in the public portal are retained by the authors and/or other copyright owners and it is a condition of accessing publications that users recognise and abide by the legal requirements associated with these

- Users may download and print one copy of any publication from the public portal for the purpose of private study or research.

- You may not further distribute the material or use it for any profit-making activity or commercial gain

If the publication is distributed under the terms of Article $25 \mathrm{fa}$ of the Dutch Copyright Act, indicated by the "Taverne" license above, 


\title{
Daytime sleep duration and the development of childhood overweight: the KOALA Birth Cohort Study
}

\author{
R. Bolijn', J. S. Gubbels ${ }^{1}$, E. F. C. Sleddens ${ }^{1}$, S. P. J. Kremers ${ }^{1}$ and C. Thijs ${ }^{2}$
}

${ }^{1}$ Department of Health Promotion, NUTRIM School for Nutrition, Toxicology and

Metabolism, Maastricht University, Maastricht, The Netherlands; ${ }^{2}$ Department of Epidemiology, CAPHRI School for Public Health and Primary Care, Maastricht University, Maastricht, The Netherlands

Address for correspondence: Dr J Gubbels, Department of Health Promotion, Maastricht University, PO Box 616, NL-6200 MD Maastricht, The Netherlands. E-mail:

jessica.gubbels@maastrichtuniversity.nl

Received 25 June 2014; revised 2 April 2015; accepted 1 May 2015

\section{Summary}

Reduced nighttime sleep is a risk factor for childhood overweight, but the association between daytime sleep and overweight is unknown. The aim of this study is to evaluate daytime sleep duration as an independent risk factor for childhood overweight. Data from the KOALA Birth Cohort Study on daytime and nighttime sleep at 2 years $(N=2322)$, and body mass index $(\mathrm{BMI})$ around 2, 5, 6, 7, 8 and 9 years were used. Multivariable general estimating equation regression analyses were performed to examine the associations of sleep duration with BMI (linear) and overweight (logistic). No associations between daytime sleep and BMl or overweight were found, whereas longer nighttime sleep was associated with lower BMI and lower risk of overweight persisting up to age 9. Daytime sleep duration is probably less relevant for prevention of childhood overweight.

Keywords: Children, napping, overweight, sleep duration.
Several meta-analyses and reviews have shown an inverse association between sleep duration and childhood overweight (1-5). However, few studies acknowledged the difference between daytime and nighttime sleeping (6-9), although sleeping in the daytime (or napping) is very common for pre-school children $(10,11)$ and is important for children's cognitive development $(12,13)$. Previous studies have shown no association between daytime sleep and childhood obesity (6), no mediation of the association between reduced sleep and overweight by daytime sleep (7), and indicated that daytime sleeping does not function as a substitute of nighttime sleeping due to different biological functions (8). However, these studies only examined daytime sleeping cross-sectionally (6), measured napping as a variable together with resting and laying down (7), or only measured daytime sleeping to complete total sleep duration (9). Exploring daytime sleep as an independent risk factor in relation to childhood overweight in a longitudinal setting could provide more insight in its significance in the prevention of childhood overweight. Thus, the aim of this study is to examine the short- and long-term associations between daytime sleeping and childhood overweight development, independently of nighttime sleeping.

Data originated from the KOALA Birth Cohort Study and were collected through frequent questionnaires completed by the parents. Women were recruited during pregnancy from a study on pregnancy-related pelvic girdle pain ('conventional' recruitment group). Other pregnant women were recruited through anthroposophic (e.g. restricted use of vaccinations, antibiotics) doctors and midwives, organic food shops and dedicated magazines, and were more likely to have an 'alternative' lifestyle regarding, for instance, children's dietary habits or medication use ('alternative' recruitment group). A total of 2834 children originated from these groups (2343 conventional and 491 alternative) (14). Informed consent was signed by all parents, and ethical approval was obtained by the Maastricht University/University Hospital Maastricht Medical Ethics Committee.

Parents reported children's daytime and nighttime sleeping (in hours) at age 2 ('How many hours does your child sleep per day?: at night ... hours; during the day ... hours'), as well as their height and weight to calculate their body mass index (BMl, weight/height $\left.{ }^{2}\right)$. BMl scores were recoded into $B M I z$-scores, adjusting for age and gender (15). A BMl $z$-score above the 85th percentile (z-score $>1.03$ ) was classified as overweight and above the 95th percentile (z-score >1.64) as obese (16). The covariates used for this study are displayed in Table 1. Missings in covariates (Table 1) were imputed from all other variables (except from follow-up BMI) using regression with addition of residuals from random cases. Data were analysed using SPSS 19.0. To examine the independent association between daytime and nighttime sleeping and BMI z-score at age 2, linear regression analysis was performed, correcting for potential confounding by covariates. Similarly, logistic regression analysis was used for overweight at age 2. Furthermore, general estimating equation (GEE) 


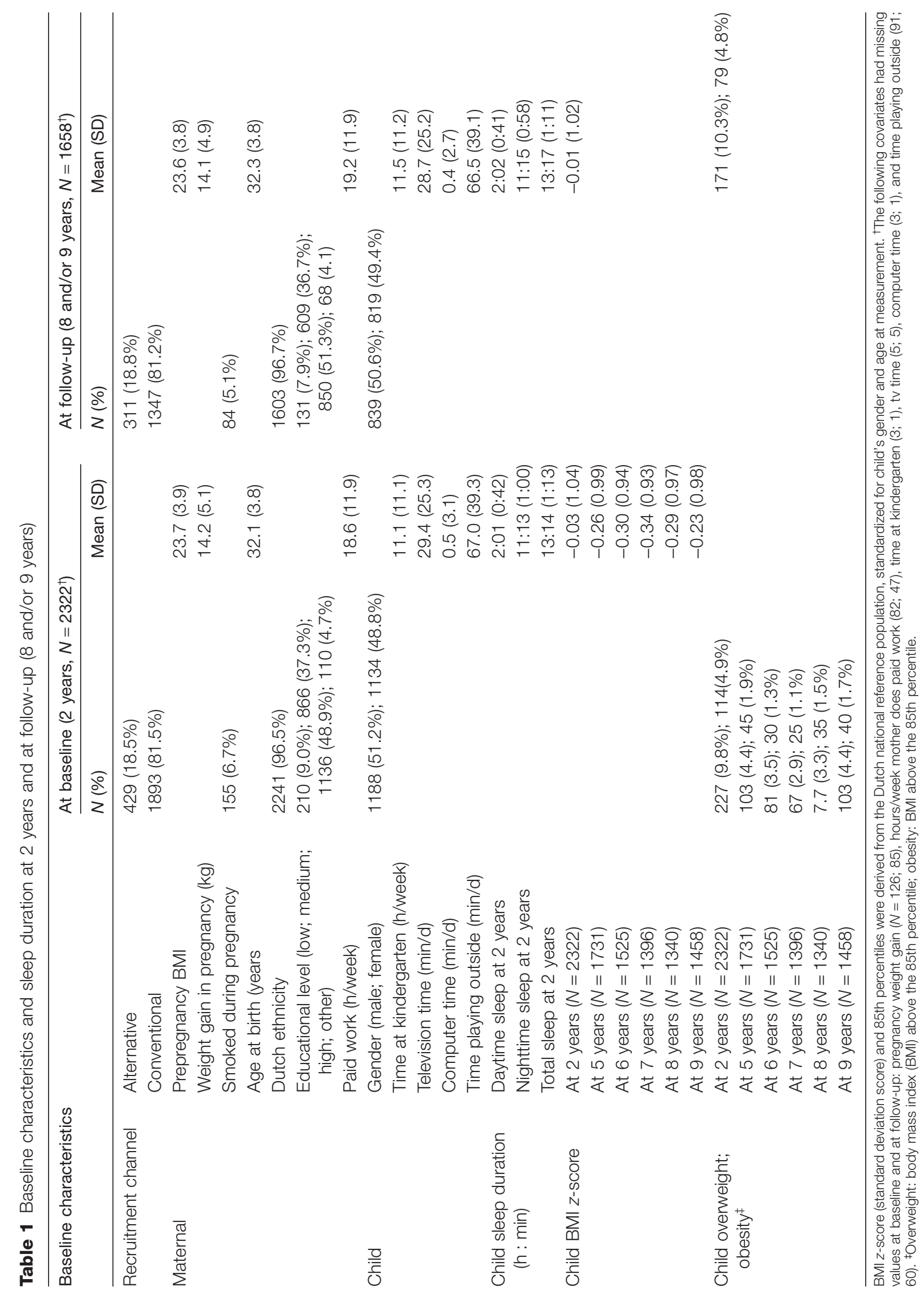


Table 2 Associations between sleep duration and body mass index/overweight

\begin{tabular}{|c|c|c|c|c|c|c|}
\hline \multirow{3}{*}{$\begin{array}{l}\text { Sleep duration }(h) \text { at age } \\
2 \text { years }\end{array}$} & \multicolumn{3}{|c|}{ Cross-sectional analysis $(N=2322)$} & \multicolumn{3}{|c|}{ Longitudinal analysis (GEE) $(N=1340-1731)^{\star}$} \\
\hline & \multicolumn{3}{|c|}{ BMI $z$-score at age $2^{\dagger}$} & \multicolumn{3}{|c|}{ BMI $z$-score at age 5 through $9^{\ddagger}$} \\
\hline & Beta & $(95 \% \mathrm{Cl})$ & $P$-value & Beta & $(95 \% \mathrm{Cl})$ & $P$-value \\
\hline Daytime & 0.003 & $(-0.058 ; 0.063)$ & 0.93 & -0.011 & $(-0.065 ; 0.043)$ & 0.70 \\
\hline Nighttime & -0.040 & $(-0.083 ; 0.003)$ & 0.069 & -0.082 & $(-0.120 ;-0.044)$ & $0.00003^{\star \star \star}$ \\
\hline \multirow{2}{*}{$\begin{array}{l}\text { Sleep duration }(h) \text { at age } \\
2 \text { years }\end{array}$} & \multicolumn{3}{|c|}{ Overweight at age $2^{\S}$} & \multicolumn{3}{|c|}{ Overweight from age 5 through 9 " } \\
\hline & Odds ratio & $(95 \% \mathrm{Cl})$ & $P$-value & Odds ratio & $(95 \% \mathrm{Cl})$ & $P$-value \\
\hline Daytime & 0.93 & $(0.79-1.10)$ & 0.40 & 1.10 & $(0.91-1.33)$ & 0.31 \\
\hline Nighttime & 0.90 & $(0.80-1.01)$ & 0.064 & 0.86 & $(0.76-0.97)$ & $0.017^{\star}$ \\
\hline
\end{tabular}

${ }^{*} \mathrm{p}<0.05 ;{ }^{* \star *} \mathrm{p}<0.001$. Statistically significant results $(P<0.05)$ are printed bold. In all analyses, nighttime and daytime sleep duration were entered together in the same model (so that their independent effects are estimated) and were adjusted for recruitment group, prepregnancy body mass index (BMI), maternal smoking during pregnancy, pregnancy weight gain, maternal age at birth, country of birth, educational level, hours/week mother does paid work, exact age of child at BMl measurement, child gender, time at kindergarten, tv time, computer time, and time playing outside. ${ }^{*}$ Number of subjects depending on age of follow-up from age 5 through 9 years (see Table 1). 'Regression coefficients (Beta) from linear regression analysis. The regression coefficient Beta indicates the increase of BMI z-score (standard deviation score) for an increment of $1 \mathrm{~h}$ of sleep. ${ }^{\ddagger}$ ldem for repeated measurements of BMl $z$-score at ages 5, 6, 7, 8 and 9 (general estimation equations), controlling also for exact age of BMl measurement; correlation structure: independent. $\S$ Odds ratios from the logistic regression analysis. The odds ratios indicate the increase of the odds of overweight (85th percentile of the Dutch national reference population) for an increment of $1 \mathrm{~h}$ of sleep. Overweight includes obesity in this analysis. "Idem for repeated assessment of overweight at ages $5,6,7,8$ and 9 (general estimation equations), controlling also for exact age of BMl measurement; correlation structure: unstructured.

regression analyses were performed to examine the longitudinal associations between sleep duration and BMI (linear GEE) and overweight (logistic GEE) at ages 5, 6, 7, 8 and 9 years. Persistence of associations over time of follow-up was evaluated by testing for interaction by age at the BMI measurement.

The number of questionnaires returned at 2 years was 2578 (91.0\% of the original cohort), and data on sleep and BMl were complete for 2322 (81.9\%) children at age 2 years. Follow-up was complete (i.e. BMl z-score was known at 8 and/or 9 years) for 1658 (58.5\%) children. Table 1 displays background characteristics of the children at baseline and of the children with complete follow-up, $\mathrm{BMl} z$-scores and percentages of overweight and obesity at different ages. No correlation was found between daytime and nighttime sleep at 2 years $(r=0.005$; $P=0.805, N=2322$ ).

In longitudinal analysis (GEE; Table 2), BMl z-scores and overweight at ages 5, 6, 7, 8 and 9 years were associated with nighttime but not daytime sleep duration. When adjusted for baseline BMI z-score at age 2, the result for nighttime sleep was attenuated but remained highly significant (beta $=-0.054,95 \% \mathrm{Cl}=-0.088$ to -0.020 , $P=0.002$ for BMl $z$-score at ages $5,6,7,8$ and 9 , i.e. a 0.054 lower BMl z-score through 5, 6, 7, 8 and 9 years for each hour increment in night sleep, and interactions with age of BMI measurement were non-significant, both indicating that the effect of nighttime sleep duration was lasting beyond the contemporaneous association at age 2 .

The results indicate that longer nighttime sleeping decreases the risk of developing overweight, confirming previous research (1-5). Several pathways may explain the effects of reduced sleep on weight gain. The hormonal pathway explains the disrupted appetite regulation due to reduced sleep: in case of sleep loss, leptin levels (satiety hormone) are low and ghrelin levels (appetite hormone) are high, causing more hunger, and therefore, the likelihood to consume more food (17). Moreover, disrupted hormone levels may also promote the storage of excess visceral adipose (18). A behavioural pathway may explain the effects of reduced sleep as well: more opportunities to eat are created during the extra time a child is awake (4), and obesogenic food in particular is more likely to be consumed (19). Furthermore, tiredness caused by sleep loss can reduce the amount of physical activity and increase the time spent being sedentary (4), which successively promotes consumption of obesogenic food (20).

The current study found, in line with previous indications $(6,8)$, no association between daytime sleeping at 2 years and BMl or overweight. These findings seem to support the hormonal pathway over the behavioural pathway in explaining the relation between nighttime sleep and overweight. If overweight would be the result of unhealthy behaviour caused by reduced nighttime sleeping (i.e. more opportunities to consume obesogenic food, and/or less physical activity and more time spent being sedentary due to tiredness) $(4,17,19,20)$, longer daytime sleep duration would also protect against this unhealthy behaviour and therefore against overweight. However, no association between daytime sleeping and childhood overweight was found. Also, no correlation was found between daytime and nighttime sleeping, indicating that nighttime sleeping is not a mediator of daytime sleeping.

An important limitation of this study is the parentreported data on sleep and $\mathrm{BMI}$, which might introduce bias, although this method is used in all previous studies on the relationship between sleep and overweight in children, and alternatives such as observation are not considered feasible in large-scale studies. The overrepresentation of families with an 'alternative lifestyle' and highly educated parents, the low overweight percentages of the participants, and large dropout of participants 
possibly limit the generalizability of our findings. However, the average sleep duration (both nighttime and daytime) of the children in the current study is similar to other studies (10) and Table 1 shows that the differences in baseline characteristics between the children at baseline and at follow-up are very small, rendering it very unlikely that differential dropout would have biased the results of the longitudinal analysis. This study was, to our knowledge, the first study examining daytime sleep, in addition to nighttime sleep, as a potential independent risk factor for longitudinal childhood overweight development from preschool into school age.

In conclusion, our study confirms that daytime sleep duration is less relevant for childhood overweight prevention.

\section{Conflict of Interest Statement}

No conflict of interest was declared.

\section{Financial disclosure}

The authors declare that they have no financial interests related to this work.

\section{Funding source}

Financial support for the KOALA Birth Cohort Study until 7-8 years of follow-up was provided by the Triodos Foundation, Phoenix Foundation, Raphaël Foundation, Iona Foundation, and Foundation for the Advancement of Heilpedagogie, Friesland Nutrition (presently Friesland Campina), the Dutch Sugar Foundation, the Dutch Ministry of Economic Affairs, the Netherlands Organization for Health Research and Development (ZonMw Project No. 2100.0090), the Netherlands Asthma Foundation (Grants Nos. 3.2.03.48 and 3.2.07.022), the Netherlands Heart Foundation (Grant No. 2008B112), and Maastricht University (Kootstra fellowship of J. Gubbels and E. Sleddens), all in the Netherlands. The sponsors had no influence on the data analysis and publication of the results.

\section{Author contributions}

Renee Bolijn carried out the initial analyses, drafted the initial manuscript and approved the final manuscript as submitted.

Jessica S. Gubbels conceptualized the study, was involved in the data collection, was involved in the analyses and interpretation of the data, critically reviewed and revised the manuscript, and approved the final manuscript as submitted.

Ester F.C. Sleddens was involved in the data collection, was involved in the interpretation of the data, critically reviewed and revised the manuscript, and approved the final manuscript as submitted.

Stef P.J. Kremers was involved in the data collection, critically reviewed and revised the manuscript, and approved the final manuscript as submitted.
Carel Thijs initiated and supervised the KOALA Birth Cohort Study, coordinated the data collection, was involved in the analyses and interpretation of the data, critically reviewed the analyses and manuscript, and approved the final manuscript as submitted.

\section{References}

1. Patel SR. Reduced sleep as an obesity risk factor. Obes Rev 2009; 10: 61-68.

2. Chen X, Beydoun MA, Wang Y. Is sleep duration associated with childhood obesity? A systematic review and meta-analysis. Obesity (Silver Spring) 2008; 16: 265274.

3. Marshall NS, Glozier N, Grunstein RR. Is sleep duration related to obesity? A critical review of the epidemiological evidence. Sleep Med Rev 2008; 12: 289-298.

4. Patel SR, Hu FB. Short sleep duration and weight gain: a systematic review. Obesity (Silver Spring) 2008; 16: 643653.

5. Van Cauter E, Knutson KL. Sleep and the epidemic of obesity in children and adults. Eur J Endocrinol 2008; 159: S59-S66.

6. Jiang F, Zhu S, Yan C, Jin X, Bandla H, Shen X. Sleep and obesity in preschool children. J Pediatr 2009; 154 : 814-818.

7. Snell EK, Adam EK, Duncan GJ. Sleep and the body mass index and overweight status of children and adolescents. Child Dev 2007; 78: 309-323.

8. Bell JF, Zimmerman FJ. Shortened nighttime sleep duration in early life and subsequent childhood obesity. Arch Pediatr Adolesc Med 2010; 164: 840-845.

9. Klingenberg L, Christensen LB, Hjorth MF. No relation between sleep duration and adiposity indicators in 9-36 months old children: the SKOT cohort. Pediatr Obes 2012; 8: E14-E18.

10. Iglowstein I, Jenni OG, Molinari L, Largo RH. Sleep duration from infancy to adolescence: reference values and generational trends. Pediatrics 2003; 111: 302-307.

11. Crosby B, LeBourgeois MK, Harsh J. Racial differences in reported napping and nocturnal sleep in 2- to 8-year-old children. Pediatrics 2005; 115: 225-232.

12. Gómez RL, Bootzin RR, Nadel L. Naps promote abstraction in language-learning infants. Psycho/ Sci 2006; 17: 670-674.

13. Hupbach A, Gómez RL, Bootzin RR, Nadel L. Napdependent learning in infants. Dev Sci 2009; 12: 10071012.

14. Kummeling I, Thijs C, Penders J, et al. Etiology of atopy in infancy: the KOALA Birth Cohort Study. Pediatr Allergy Immunol 2005; 16: 679-684.

15. Fredriks AM, Van Buuren S, Wit JM, VerlooveVanhorick SP. Body index measurements in 1996-7 compared with 1980. Arch Dis Child 2000; 82: 107112.

16. Barlow SE. Expert committee recommendations regarding the prevention, assessment, and treatment of child and adolescent overweight and obesity: summary report. Pediatrics 2007; 120: S164-S192. 
17. Knutson KL, Van Cauter E. Associations between sleep loss and increased risk of obesity and diabetes. Ann N Y Acad Sci 2008; 1129: 287-304.

18. Sokolovic N, Kuriyan R, Kurpad AV, Thomas T. Sleep and birthweight predict visceral adiposity in overweight/ obese children. Pediatr Obes 2013; 8: e41-e44.

19. Hjorth MF, Quist JS, Andersen R, et al. Change in sleep duration and proposed dietary risk factors for obesity in danish school children. Pediatr Obes 2014; 9: e156e159.

20. Arora T, Hosseini-Araghi M, Bishop J, Yao GL, Thomas GN, Taheri S. The complexity of obesity in U.K. adolescents: relationships with quantity and type of technology, sleep duration and quality, academic performance and aspiration. Pediatr Obes 2013; 8: 358366. 